\title{
A Retrospective Surveillance Study on Emergence and Consistency of Influenza like Illness Caused by Influenza Strains over a Period of Three Decades in Solan, (Himachal Pradesh), India
}

Arti Bharmoria ${ }^{1 *}$, Vipin Behari Vaish ${ }^{2}$, Ashish Chaurasia ${ }^{3}$ and Tahlan $\mathrm{AK}^{4}$

${ }^{1}$ Quality Assurance Division, Central Research Institute, Kasauli, H.P, India

${ }^{2}$ National Influenza SurveillanceCentre, Central Research Institute, Kasauli, India

${ }^{3}$ NISC, Central Research Institute, Kasauli, H.P, India

${ }^{4}$ Central Research Institute, Kasauli, H.P. India

\begin{abstract}
In connectivity to the introduction of frequent epidemics of influenza A (H3N2, H1N1), the Influenza Surveillance Projects has monitored the burden of influenza in the outpatients through population-based surveillance. WHO is playing an active role by keeping an eye on status of seasonal as well as epidemic strains of influenza by its surveillance throughout the world. The present study offers the status of ongoing surveillance influenza at National Influenza Surveillance Centre (NISC), Central Research Institute (CRI), Kasauli for the emergence and consistency of influenza strains for current as well as over a period of three decades in Solan, Himachal Pradesh. From 1980 to 2015, various clinical centers of Himachal reported counts of influenza-like illness (fever including cough or sore throat). During these years, the respiratory specimens of 6581 patients showing influenza-like illness were collected. The incidence of visits had been calculated for influenza-like illness using the size of the patient population, and the incidence attributable to influenza was extrapolated from the proportion of patients with positive tests. Up to 2008 the egg inoculation method was used for the isolation and detection of influenza strains but in 2009 a RT-PCR equipped, fabricated BSL-3 laboratory was implanted at CRI for the isolation and detection of influenza strains. The reagents, primers and probes were supplied by NCDC, Delhi. Since 1980, 319 influenza isolates has been identified and isolated at NISC. Among these 282 were isolated by egg propagation method while 37 were processed by RT-PCR. Influenza incidence varied with age groups and by season after the pandemic of 2009 influenza A, H1N1. High levels of influenza virus circulation, especially in young Children, emphasize the need for additional efforts to increase the uptake of influenza vaccines and anti-viral. The continuous surveillance and monitoring of influenza strains is necessary to keep a check on the highly variable influenza strains to avoid the deadly incidents of influenza pandemics. In current scenario RT-PCR method is successful and appropriate method for the influenza surveillance.
\end{abstract}

Keywords: H3N2; H1N1; Influenza; N.I.S.C; RT-PCR; Surveillance; C.R.I Himachal; India

\section{Introduction}

WHO maintains Global Influenza Surveillance Network (GISN) in National Influenza Centre and WHO Collaborating centres. GISN currently comprises 122 National Influenza Centres in 87 countries and 4 WHO Collaborating Centres for Reference and Research on Influenza. Although this system has proven to be valuable, tropical and resourcelimited countries (particularly in Africa) are underrepresented [1,2]. These centres provide an early warning system for emerging strains with epidemic potential. This system is important because the efficacy of influenza vaccines is reduced if they do not contain the strains currently circulating. WHO issues recommendations for virological information used in the biannual process of selecting strains for the composition for vaccines, in February for the northern hemisphere and in September for the southern hemisphere. For 60 years, the WHO Global Influenza Surveillance Network (GISN) has provided virological information used in the biannual process of selecting strains for the Northern and Southern Hemisphere influenza vaccine formulations. However, its capacity to provide epidemiologic data or an alert of an emerging pandemic is limited.

A sentinel surveillance system is having the objectives as 1) describe the disease impact and epidemiology of severe, acute, febrile respiratory illness and define the proportion that is associated with influenza; 2) provide influenza virus isolates for monitoring changes in viral antigens and development of new vaccines; 3 ) contribute data for local pandemic planning and making decisions regarding vaccine policy; 4) provide infrastructure for an early warning system for outbreaks of new subtypes of influenza A viruses and new strains of existing subtypes; and 5) serve as a monitoring tool for pandemic influenza [1]. These data, in turn, can be used to analyze geographic, temporal, and biologic differences in circulating influenza strains and assist in monitoring for emerging unusual or critical situations, such as a pandemic. This information can guide the crucial process of strain selection for vaccine development and other prevention and control strategies, as well as aid influenza diagnosis and enhance patient care [3]. Additionally, by documenting the burden of influenza, surveillance data have helped in the past and should help in the future to increase compliance with the vaccination program.

NISC is a World Health Organization (WHO) collaborating laboratory. In 1962 an Influenza centre had been started for the development and isolation of influenza virus strains. This centre was

*Corresponding author: Arti Bharmoria, Research Associate, Quality Assurance Division, Central Research Institute, Kasauli, H.P., India, Tel: 07832065755; E-mail: artibharmoria@gmail.com

Received December 10, 2015; Accepted January 18, 2016; Published January 21 2016

Citation: Bharmoria A, Vaish VB, Chaurasia A, Tahlan AK (2016) A Retrospective Surveillance Study on Emergence and Consistency of Influenza like Illness Caused by Influenza Strains over a Period of Three Decades in Solan, (Himachal Pradesh), India. J Med Microb Diagn 5: 216. doi:10.4172/2161-0703.1000216

Copyright: (c) 2016 Bharmoria A, et al. This is an open-access article distributed under the terms of the Creative Commons Attribution License, which permits unrestricted use, distribution, and reproduction in any medium, provided the original author and source are credited. 
Citation: Bharmoria A, Vaish VB, Chaurasia A, Tahlan AK (2016) A Retrospective Surveillance Study on Emergence and Consistency of Influenza like Illness Caused by Influenza Strains over a Period of Three Decades in Solan, (Himachal Pradesh), India. J Med Microb Diagn 5: 216. doi:10.4172/2161-0703.1000216

recognized as National influenza centre by W.H.O in March 1977. This research centre had been engaged in influenza surveillance programme and allied research activities. A BSL-3 lab had been assigned to CRI under Integrated Disease Surveillance Programme of India detection of influenza-specific RNA by real-time reverse transcriptase polymerase chain reaction (Real-time RT-PCR). The surveillance of the H1N1 and local influenza isolates from the dispensary of C.R.I., Army Hospital, Kasauli, Dispensary Garkhal, and District Hospital Solan. The NISC collects and analyzes the suspected influenza samples year-round in the CRI, Kasauli and prepares influenza surveillance report providing information regarding the emergence status of the influenza virus in Himachal.

The term influenza was used to describe an apparent 'influence' of environmental factors such as cold temperature on the occurrence of this epidemic respiratory disease. Influenza is an Italian word which means the influence of stars and heavenly bodies on epidemics and cough. The terms like 'epidemic catarrh' or 'catarrhal fever' had been used for influenza $[4,5]$.

Influenza viruses belong to the family Orthomyxoviridae, which is characterized by a single stranded and segmented RNA genome. The influenza virus is a spherical or filamentous enveloped virus. The influenza viruses are classified into types $\mathrm{A}, \mathrm{B}$, and $\mathrm{C}$ on the basis of their core proteins. Influenza a virus is further classified into the subtypes like H1N1, H2N2, and H3N2, on the basis of the envelope glycoproteins known as hemagglutinin (HA) and neuraminidase (NA). $15 \mathrm{H}$ subtypes (H1-H15) and nine $\mathrm{N}$ subtypes (N1-N9) have been identified for influenza A viruses. The viruses exhibits high mutation rates and frequent genetic reassortments which contribute to great variability of the HA and NA antigens. Minor point mutations known as the antigenic drifts occur relatively often. Antigenic drift enables the virus to escape immune recognition, which is responsible for the repeated influenza outbreaks during interpandemic years. The reassortment of genetic material from different A subtypes leads to major changes in the HA antigens and these variations are known as the antigenic shifts. Type B influenza does not exhibits antigenic shifts and is not divided into subtypes like influenza A [6-8].

In humans, H1N1 swine flu presents as an influenza-like illness (ILI) with symptoms similar to seasonal influenza like fever, persistent cough, sore throat, runny nose, muscle pains, severe headache, painful swallowing, persistent congestion, weakness however, a considerable proportion of patients reported vomiting or diarrhea which is unusual in seasonal influenza. Flu symptoms may not surface until 1-2 days after counter to the flu virus and can last from 1- 2 weeks [9-12].

Influenza viruses are transmitted mainly by large droplets and small particle aerosols generated by infected people. Complications of influenza virus infections include viral pneumonia, secondary bacterial pneumonia, airway inflammation [13]. In the acute phase of illness, influenza virus can be recovered from nasopharyngeal samples by culture or directly by rapid tests. Serological diagnosis appropriately spaced, paired sera.

The influenza viruses can be characterized through one or more tests including genome sequencing, hemagglutination inhibition (HI) and/or neutralization assays. WHO is using this data to compare how similar currently circulating influenza viruses are to the reference viruses used for developing influenza vaccines, and to monitor for changes in circulating influenza viruses. Historically $\mathrm{HI}$ data has been used most commonly to assess the similarity between reference viruses and circulating viruses as a proxy for vaccine effectiveness. However genetic characterization is performed nowadays to determine the genetic group identity of circulating viruses so that antigenic properties of these viruses can be inferred.

It is imperative to have specific and sensitive virus detection systems available for rapid diagnosis of influenza. Traditionally, the gold standard has been virus isolation from nasopharyngeal swabs using embryonated hen eggs. Other diagnostic tests employed include virus culture in Madin Darby canine kidney cells or measurement of a rise in antibody titer in paired sera by hemagglutination inhibition assay. These established techniques are time consuming and laborious. Furthermore, the sensitivity of virus isolation is dependent on the presence of infectious particles and some virus strains are difficult to isolate. Serology provides only retrospective data which do not facilitate prompt intervention and appropriate case management. In recent years enzyme-linked immunosorbent assays (ELISA) and reverse transcription (RT)-PCR have been introduced in some laboratories to provide more timely results although the sensitivity of the former has been shown to be quite variable [14].

Molecular diagnosis of influenza A by real-time RTPCR can be a rapid assay: results, including subtyping, may be available in less than 1 day. RT-PCR can provide increased sensitivity in the detection of influenza virus, which can be used to enhance community and hospital surveillance programs and hasten the specific diagnosis of influenza among ill patients.

Annual influenza epidemics are responsible for the death of 250,000-500,000 people worldwide and cause illness in (5-15) \% of the total population each year [15]. Human influenza occurs all over the world with annual global attack rate of fever or myalgia, headache, malaise or non-productive cough. Most people usually recover without requiring any medical treatment. In very young or elderly and, in chronically ill people, infection sometimes leads to the death [16].

In India, in 2009 the influenza pandemic due to Influenza a (H1N1) 09 (pdm H1N1) began in May 2009, spread to all over the world and became global by July 112009 . On 10th August 2010, the pandemic was declared to be an end with more than 18,449 deaths reported worldwide by end of the month. The first positive case of pdm H1N1 was reported in May 2009 and by end of the year 2010, 20604 cases with 1763 deaths were reported. The country experienced three waves during the period of pandemic of 2009-2010, first one in 2009 September, followed by second wave in December, and the third peak in August 2010 when the end of pandemic was declared $[9,17,18]$.

After 2010, pdm H1N1 reappeared in several northern and western states of the country during the winter months of 2012-2013. The resurgence since December 2014 however appears to be worse than the previous one, leading to over 30,000 cases and 2000 deaths countrywide (as of 28th March,2015) as compared to 5044 cases and 405 deaths in 2012 and 5250 cases and 692 deaths in 2013. The resurgent waves lead to more number of hospitalizations and deaths due to pdmH1N1 as compared to the rest part of the year and appear at an interval of 1.5-2 years $[17,18]$.

\section{Materials and Methods}

The nasopharyngeal swabs were collected from patients showing influenza like illness determined by their clinical history [12]. The samples sent to NISC were collected from the dispensary of Central Research Institute, Army Hospital Kasauli, dispensary Garkhal, Dharampur and Zonal Hospital Solan. However during the time of epidemics the samples were received from Haryana and Punjab. 
Citation: Bharmoria A, Vaish VB, Chaurasia A, Tahlan AK (2016) A Retrospective Surveillance Study on Emergence and Consistency of Influenza like Illness Caused by Influenza Strains over a Period of Three Decades in Solan, (Himachal Pradesh), India. J Med Microb Diagn 5: 216. doi:10.4172/2161-0703.1000216

Page 3 of 5

\section{Egg isolation method}

isolation for the influenza samples had been carried out at NISC before 2009. The clinical samples i.e. throat washings and throat swabs were collected from the patients showing influenza like symptoms in sterile Earle's balanced salt solution and sent to the laboratory at temperature $4^{\circ} \mathrm{C}$. The samples were then centrifuged in refrigerated centrifuge to remove the debris and gentamycin at concentration of 10 $\mu \mathrm{gm} / \mathrm{ml}$ was added to each sample. The viral samples were inoculated by the amniotic and allantoic route to the white leghorn chicken eggs. The eggs were incubated in humidified incubator having temperature $34^{\circ} \mathrm{C}$ and humidity (40-50) \%.

After completion of incubation the amniotic and allantoic fluid were harvested from the eggs and dterility test were performed [19]. The hemagglutination test was performed on the sterile harvested fluids by using $0.5 \%$ chicken RBCs. The sterile samples showing the HA activity were considered positive and were used for further identification tests by HAI while the negative samples were discarded. For identification of the influenza strains the reference antiserums provided by the CDC Atlanta were used [20,21].

\section{RT-PCR method}

The RT-PCR tests were performed in the BSL-3 laboratory of NISC. The clinical samples were collected in the vials containing virus transport medium (VTM) (HiviralTM Transport Kit-Himedia). Thorough cold chain was maintained while transporting the samples to the laboratory. The samples were processed in Biosafety cabinet type and further stored as conveniently sized aliquots at $-80^{\circ} \mathrm{C}$ deep freezer until further use. All the reagents used in RT-PCR were WHO certified as well as the reference strains used for the testing were also provided by C.D.C., Atlanta/NCDC Delhi.

Real-time RT PCR, following CDC's protocol is performed on the samples to detect the positive H1N1 cases. The positive, negative and internal controls were included in each run as per the protocol. If there is any positive case then the sample is forwarded to the NCDC Delhi for retesting/confirmation. NCDC retest the samples by RT-PCR and confirms the H1N1 cases.

Clinical specimens were treated with a QIAamp viral kit- QIAGEN for the RNA isolation. Each sample RNA extract was tested by separate primer/probe sets: InfA, Universal swine (swFluA), Swine H1 (swH1) and RNaseP (RP). The RNaseP primer and probe set targets the human RNase $P$ gene and thus serves as an internal positive control for human nucleic acid. No template controls (NTC) and positive template controls (PTC) for all primer/probe sets should be included in each run. Human specimen control (HSC) provides a secondary negative control that validates the nucleic extraction procedure and reagent integrity.

Reaction assay mixtures were made as cocktail and dispensed into the 96-well reaction plate. Water and extracted nucleic acid or positive template controls were then added to the appropriate test reactions and controls. Cocktail preparation for RT-PCR was prepared using the AGPATH kit which included the Nucleases free water, Forward Primer, Reverse Primer, Probe, Enzyme mix, PCR master mix. Nx20 $\mu \mathrm{l}$ of master mix was used for $\mathrm{N}$ samples. While performing the test the NTC were added at first before any of the sample was added to check for contamination in the master mix. HSC was added after the samples had been added to check for cross contamination during sample preparation or addition. PTCs were added at last after all samples and NTCs were sealed.

\begin{tabular}{|c|c|c|c|c|c|}
\hline \multicolumn{3}{|c|}{ Decade I } & \multicolumn{3}{|c|}{ Decade II } \\
\hline Year & $\begin{array}{l}\text { No. of clinical } \\
\text { Specimens } \\
\text { collected }\end{array}$ & No. of isolates & Year & $\begin{array}{l}\text { No. of clinical } \\
\text { Specimens } \\
\text { collected }\end{array}$ & $\begin{array}{l}\text { No. of } \\
\text { isolates }\end{array}$ \\
\hline 1980 & 234 & 60 & 1991 & 235 & Nil \\
\hline 1981 & 183 & 61 & 1992 & 170 & Nil \\
\hline 1982 & 182 & 36 & 1993 & 243 & Nil \\
\hline 1983 & 165 & 50 & 1994 & 167 & Nil \\
\hline 1984 & 275 & 69 & 1995 & 190 & Nil \\
\hline 1985 & 508 & 2 & 1996 & 92 & Nil \\
\hline 1986 & 322 & Nil & 1997 & 228 & Nil \\
\hline 1987 & 186 & Nil & 1998 & 89 & Nil \\
\hline 1988 & 207 & Nil & 1999 & 50 & Nil \\
\hline 1989 & 284 & Nil & \multirow{2}{*}{2000} & \multirow{2}{*}{49} & \multirow{2}{*}{ Nil } \\
\hline 1990 & 229 & Nil & & & \\
\hline \multicolumn{3}{|c|}{ Decade III } & \multicolumn{3}{|c|}{$\begin{array}{l}\text { RT-PCR method had been adopted in } \\
2009\end{array}$} \\
\hline 2001 & 25 & Nil & 2009 & 123 & 35 \\
\hline 2002 & 156 & Nil & 2010 & 152 & Nil \\
\hline 2003 & 110 & Nil & 2011 & 183 & Nil \\
\hline 2004 & 112 & Nil & 2012 & 95 & Nil \\
\hline 2005 & 90 & Nil & 2013 & 166 & 2 \\
\hline 2006 & 106 & Nil & 2014 & 93 & Nil \\
\hline 2007 & 109 & Nil & \multirow{2}{*}{2015} & \multirow{2}{*}{64} & \multirow{2}{*}{ Nil } \\
\hline 2008 & 292 & Nil & & & \\
\hline
\end{tabular}

Table 1: Retrospective influenza isolation surveillance data from year 1980 to 2015 .

The thermal profile used for the processes were followed as reverse transcription ' $\mathrm{HOLD}$ ' at $55^{\circ} \mathrm{C}$ for 30 minutes. Inactivation of reverse transcriptase was done by 'HOLD' at $95^{\circ} \mathrm{C}$ for 10 minutes. The PCR amplification was carried by pursuing 45 cycles at $95^{\circ} \mathrm{C}$ for 15 seconds. A positive and negative control for the master mix was included with each assay.

\section{Results}

The surveillance of influenza virus at NISC, C.R.I had been ongoing since 1962. The surveillance system followed for influenza virus detection and isolation before 2008 was based on egg propagation technology. As with the modernization of technologies and increase in the influenza incidence reports a BSL-3 lab was set up and RT-PCR detection system for the surveillance was adopted.

In between 1980 to 2008 total numbers of clinical samples collected at NISC were 5288 (Table 1). During this period the samples were processed in embryonated eggs and total positive isolates were found to be 282 . Among these 282 samples, 219 samples were positive for H3N2, 61 samples were positive for H1N1 while 2 samples were of influenza type B positive cases. It clearly shows that the influenza a types $\mathrm{H} 3 \mathrm{~N} 2$ and H1N1 had been in circulation in the area of Solan district in past thirty years more in comparison to influenza B. However it was clearly depicted from these results that among total samples processed during these years, $5.332 \%$ of the total ILI were actually influenza cases (Table 2 ).

In 2009 the influenza epidemic wave was undergoing and the samples were received from various regions of India. Since 2009 to 2015, total clinical samples collected were 1293, among which 37 isolates were H1N1 positive. It was $2.861 \%$ of the total sample processed within 7 years (Table 2). However the ILI cases ratio was increased during 20092015 as the virus had been in circulation during this time period and hence the people had been suffering from complications identical to influenza and an increase in the hospital visits were observed. The rise in the ILI cases was found to be $27.7 \%$ in 2009 to 2015 as compared to past years of 2001 to 2008 . 
Citation: Bharmoria A, Vaish VB, Chaurasia A, Tahlan AK (2016) A Retrospective Surveillance Study on Emergence and Consistency of Influenza like Illness Caused by Influenza Strains over a Period of Three Decades in Solan, (Himachal Pradesh), India. J Med Microb Diagn 5: 216. doi:10.4172/2161-0703.1000216

Page 4 of 5

The isolated strains were processed by Hemagglutination inhibition test for the identification by the reference antiserum provided by CDC. These strains were further identified by CDC Atlanta and for confirmation of their identification (Table 3).

To analyse the trends on going in the district, the cumulative analysis for the isolates obtained in year 2009 and 2013 were verified. Main regions of outbreaks during this period were Shimla, Chandigarh, Panchkula, Kasauli, and Solan. However the isolates were obtained from other regions like Chennai and Andhra Pradesh were also included in these results. The main factors included in the study were the data of age, season of isolation and gender ratio (Table 4).

The maximum positive cases were falling in the age group of 10 20 years which is the $29.729 \%$ of total cases. Influenza positive cases were seen in months of August, September, October and November only. In other months the cases were found negative for H1N1 as well as H3N2. The most frequently identified influenza virus type reported by laboratory was influenza-A viruses, with influenza H3N2 viruses predominating. The ratio of males and females were almost similar and were found to be $51.35 \%$ of males affected and $48.65 \%$ of females affected by influenza infections.

\begin{tabular}{|c|c|c|c|c|}
\hline S. No. & Details & $\begin{array}{c}\text { 1980-2008 } \\
\text { (Egg Isolation } \\
\text { Method) }\end{array}$ & $\begin{array}{c}\text { 2008-2015 } \\
\text { (RT-PCR } \\
\text { Method) }\end{array}$ & Total Cases \\
\hline 1 & $\begin{array}{c}\text { Total number of throat } \\
\text { swabs collected }\end{array}$ & 5288 & 1277 & 6581 \\
\hline 2 & $\begin{array}{c}\text { Total number } \\
\text { processed in eggs }\end{array}$ & 5288 & Nil & 5288 \\
\hline 3 & $\begin{array}{c}\text { Samples tested by RT- } \\
\text { PCR }\end{array}$ & Nil & 1293 & 1277 \\
\hline 4 & $\begin{array}{r}\text { Total No. of positive } \\
\text { isolates }\end{array}$ & 282 & 37 & 319 \\
\hline 5 & \% of positive samples & $5.332 \%$ & $2.861 \%$ & $4.859 \%$ \\
\hline 6 & Positive for Influenza A & H3N2- 219 & H3N2- Nil & H3N2- 219 \\
\hline 7 & Positive for Influenza B & 02 & H1N1-35 & H1N1- 96 \\
\hline
\end{tabular}

Table 2: Comparative Surveillance Records by egg isolation method versus RTPCR method.

\begin{tabular}{|c|c|c|c|c|}
\hline Year & $\begin{array}{l}\text { No. of clinical } \\
\text { specimens } \\
\text { collected }\end{array}$ & $\begin{array}{l}\text { No. of } \\
\text { isolates }\end{array}$ & Identification Results & $\begin{array}{l}\text { Type of } \\
\text { Influenza }\end{array}$ \\
\hline 1980 & 234 & 60 & $\begin{array}{c}\text { Similar to A Victoria/3/75 } \\
\text { (H3N2) }\end{array}$ & Type A \\
\hline 1981 & 183 & 61 & $\begin{array}{c}\text { Similar to } A / B r a z i l / 11 / 78 \\
(\mathrm{H} 1 \mathrm{~N} 1) \text { and } \mathrm{A} / \\
\text { Bangkok/1/79 (H3N2) }\end{array}$ & Type A \\
\hline 1982 & 182 & 36 & $\begin{array}{c}\text { Similar to } A / B r a z i l / 11 / 78 \\
(\mathrm{H} 1 \mathrm{~N} 1) \text { and } \mathrm{A} / \\
\text { Bangkok/1/79 }(\mathrm{H} 3 \mathrm{~N} 2)\end{array}$ & Type A \\
\hline 1983 & 165 & 50 & $\begin{array}{c}\text { Similar to A/ } \\
\text { Bangkok/1/78 (H3N2) }\end{array}$ & Type A \\
\hline 1984 & 275 & 69 & $\begin{array}{c}\text { Similar to A/ } \\
\text { Phillipine/2/82 (H3N2) } \\
\text { and B/Singapore/222/82 }\end{array}$ & Type A and B \\
\hline 1985 & 508 & 2 & $\begin{array}{l}\text { Similar to } \mathrm{B} / \text { Texas } / 1 / 84 \\
\text { and } \mathrm{B} / \text { Kanagawal/2/84 }\end{array}$ & Type A and B \\
\hline 1989 & 284 & 4 & $\begin{array}{c}\text { Similar to A/ } \\
\text { England/427/88 (H3N2) }\end{array}$ & Type A \\
\hline 2009 & 123 & 35 & Similar to Swine H1N1 & Type A \\
\hline 2013 & 166 & 2 & $\begin{array}{c}\text { Similar to seasonal } \\
\text { H3N2 }\end{array}$ & Type A \\
\hline Total & 2120 & 319 & $\begin{array}{l}\text { All isolates were } \\
\text { identified }\end{array}$ & Type A and B \\
\hline
\end{tabular}

Table 3: Influenza identification data in past three decades 1980-2015.

\begin{tabular}{|c|c|c|c|c|c|c|c|c|}
\hline S.No & \multicolumn{2}{|c|}{ Age Factor } & \multicolumn{2}{|c|}{ Gender } & \multicolumn{2}{|c|}{ H1N1 } & \multicolumn{2}{|c|}{ H3N2 } \\
\cline { 2 - 9 } & $\begin{array}{c}\text { Age } \\
\text { Group }\end{array}$ & $\begin{array}{c}\text { Number } \\
\text { of cases }\end{array}$ & Male & Female & Male & Female & Male & Female \\
\hline 1 & $0-10$ & 7 & 4 & 3 & 3 & 3 & 1 & Nil \\
\hline 2 & $10-20$ & 11 & 5 & 6 & 5 & 5 & Nil & 1 \\
\hline 3 & $20-30$ & 6 & 4 & 2 & 2 & 1 & 2 & 1 \\
\hline 4 & $30-40$ & 7 & 3 & 4 & 3 & 4 & Nil & Nil \\
\hline 5 & $40-50$ & 5 & 2 & 3 & 2 & 3 & Nil & Nil \\
\hline 6 & $50-60$ & Nil & Nil & Nil & Nil & Nil & Nil & Nil \\
\hline 7 & $60-70$ & 1 & 1 & Nil & 1 & Nil & Nil & Nil \\
\hline 8 & Total & 37 & 19 & 18 & 16 & 16 & 3 & 2 \\
\hline 9 & Total $\%$ & 100 & 51.35 & 48.65 & 43.24 & 43.24 & 8.11 & 5.40 \\
\hline
\end{tabular}

Table 4: Cumulative analysis of RT-PCR positive cases in year 2009 and 2013 for assessment of effect of season, gender, age on influenza isolates.

\section{Conclusion}

Influenza remains a major contributor to morbidity and mortality in India and worldwide both directly and indirectly through exacerbation of underlying medical co-morbid conditions. The surveillance networks should be expanded throughout India to access the emphasis of the age factor, climatic variations, environmental variations and the seasonal impact on the influenza strains in circulation. The development of vaccines against seasonal and pandemic influenza requires careful global surveillance as well as in-depth knowledge of virology, epidemiology, and immunology. There should be an eye on the positive cases of influenza and their impact on the respective area. For this a network of connection should be established between the local hospitals and the surveillance centre for the proper identification of the influenza like illness and their diagnosis. The surveillance system needs to be more customized and the network system of hospitals and surveillance should be enhanced by applying latest technical approaches so that the influenza and influenza like illness will not go unnoticed and the chances of epidemic outbreaks should be brought down to the as minimal level as is possible.

\section{Acknowledgments}

The authors would like to thank the staff members of National Influenza Surveillance Centre, Central Research Institute, Kasauli, District-Solan, Himacha Pradesh, for their technical support during this research work.

\section{References}

1. Justin RO, Viviana S, Osvaldo C Uez, Otavio O, Deborah B, et al. (2009) Strategy to Enhance Influenza Surveillance Worldwide. Emerging Infectious Diseases 15: 1271-1278.

2. Soumen R, Ritwik D, Deepak P, Shweta T, Sandeepan M, et al. (2014) Virus Disease 25: 372-375.

3. Peng Y, Wei D, Min L, Weixian S, Xiaoming P, et al. (2009) Review of an Influenza Surveillance System, Beijing, People's Republic of China. Emerging Infectious Diseases 15: 1603-1608.

4. Grant J (1852) On influenza, as quoted in Thompson. T, Annals of Influenza or Epidemic Catarrhal Fever in great Britain from 1560 to 1837 , Sydenham Society, London, 1852, XII. Cited from: Gary R. Noble, 1982, Epidemiological and clinical aspects of influenza; (11-50) Basic and Applied Influenza Research, A.S. Beare; CRC, Press.

5. Fleming DM, Velden J van der, Paget WJ (2003) The evolution of influenza surveillance in Europe and prospects for the next 10 years. Vaccine 21: 1749-1753.

6. W.H.O (2005) H5N1 Avian influenza: First step toward development of a human vaccine. Weekly Epidemiological Records 80: 277-284.

7. Paul WG, Jordana KS, Carrie MK, Kellie JR, John O (2013) The Burden of Influenza B: A Structured Literature Review. American Journal of Public Health 103: 43-51.

8. Geertjan W (2007) Occasional review: Infl uenza in COPD: pathogenesis, prevention, and treatment. International Journal of COPD 2: 5-10. 
Citation: Bharmoria A, Vaish VB, Chaurasia A, Tahlan AK (2016) A Retrospective Surveillance Study on Emergence and Consistency of Influenza like Illness Caused by Influenza Strains over a Period of Three Decades in Solan, (Himachal Pradesh), India. J Med Microb Diagn 5: 216. doi:10.4172/2161-0703.1000216

Page 5 of 5

9. Shobha B, Harendra SC, Samander K (2009) Diagnosis of influenza viruses with special reference to novel H1N1 2009 influenza virus. Indian J Microbiology 49: 301-307.

10. Vaxa (2004) Vaxa Homopathic Medicinals, Google search engine.

11. Lahariya C, Sharma AK, Pradhan SK (2006) Avian Flu and Possible Human Pandemic. Indian Pediatrics 43: 317-325.

12. Srey VH, Sek M, Sareth Rith, Sovann L, Seng H, et al. (2014) Epidemiological and Virological Characteristics of Influenza Viruses Circulating in Cambodia from 2009 to 2011. Plos One, 9: 1-14 e110713.

13. Linnemann CC, Shea L, Partin JC, Schubert WK, Schiff GM (1975) Reye's syndrome: Epidemiologic and viral studies, 1963-1975. American Journal of Epidemiology 101: 517-526.

14. Michelle Q, Eugene D, Fergus R, Sean A, Ann C (2005) Real-Time ReverseTranscription PCR for Detection and Quantitative Analysis of Equine Influenza Virus. Journal of clinical Microbiology 43: 10: 5055-5057.

15. Gupta Vishal, Earl, David J, Deem Michael W (2006) Quantifying influenza vaccine efficacy and antigenic distance. Vaccine 24: 3881-3888.
16. W.H.O. (2007) Influenza fact sheet at http://www.who.int/mediacentre/ factsheets/ fs211/ en/ (Accessed on April 27, 2007).

17. Baijayantimala M (2015) Resurgence of Influenza A (H1N1) 09: Smoldering Pandemic in India? J Glob Infect Dis 7: 56-59.

18. Tanushree D, Bhawana J, Ajay KS, Madan M, Mukesh D, et al. (2014) Influenza virus genotypes circulating in and around Lucknow, Uttar Pradesh, India, during post pandemic period,August 2010 - September 2012. Indian J Med Res 139 418-426.

19. Oxford JS, Newman R, Corcoran T, Bootman J, Major D et al. (1991) Direct isolation in eggs of influenza $A(\mathrm{H} 1 \mathrm{~N} 1)$ and $B$ viruses with haemagglutinins of different antigenic and amino acid composition. Journal of General Virology 72: $185-189$

20. Kohut ML, Arntson BA, Lee W, Rozeboom K, Yoon KJ, et al. (2004) Moderate exercise improves antibody response to influenza immunization in older adults. Vaccine 22: 2298-2306.

21. Rao BL, Chada MS, Kulkarni PB, Yeolekar LR (2001) Seroepidemiology of Influenza in Pune, India. Indian Journal of Medical Research 114: 121-126. 